\title{
The paracrine effect of adipose-derived stem cells inhibits osteoarthritis progression
}

\author{
Kazunari Kuroda ${ }^{1}$, Tamon Kabata ${ }^{*}$, Katsuhiro Hayashi ${ }^{1}$, Toru Maeda ${ }^{1}$, Yoshitomo Kajino $^{1}$, Shintaro Iwai ${ }^{1}$, \\ Kenji Fujita', Kazuhiro Hasegawa', Daisuke Inoue ${ }^{1}$, Naotoshi Sugimoto ${ }^{2}$ and Hiroyuki Tsuchiya $^{1}$
}

\begin{abstract}
Background: This study aimed to determine whether intra-articularly injected adipose-derived stem cells (ADSCs) inhibited articular cartilage degeneration during osteoarthritis (OA) development in a rabbit anterior cruciate ligament transection (ACLT) model. The paracrine effects of ADSCs on chondrocytes were investigated using a co-culture system.

Methods: ACLT was performed on both knee joints of 12 rabbits. ADSCs were isolated from the subcutaneous adipose tissue. ADSCs with hyaluronic acid were intra-articularly injected into the left knee, and hyaluronic acid was injected into the right knee. The knees were compared macroscopically, histologically, and immunohistochemically at 8 and 12 weeks. In addition, cell viability was determined using co-culture system of ADSCs and chondrocytes.

Results: Macroscopically, osteoarthritis progression was milder in the ADSC-treated knees than in the control knees 8 weeks after ACLT. Histologically, control knees showed obvious erosions in both the medial and lateral condyles at 8 weeks, while cartilage was predominantly retained in the ADSC-treated knees. At 12 weeks, the ADSC-treated knees showed a slight suppression of cartilage degeneration, unlike the control knees.

Immunohistochemically, MMP-13 expression was less in the ADSC-treated cartilage than in the control knees. The cell viability of chondrocytes co-cultured with ADSCs was higher than that of chondrocytes cultured alone. TNF-alpha-induced apoptotic stimulation was similar between the two groups.

Conclusions: Intra-articularly injected ADSCs inhibited cartilage degeneration progression by homing to the synovium and secreting a liquid factor having chondro-protective effects such as chondrocyte proliferation and cartilage matrix protection.
\end{abstract}

\section{Background}

Osteoarthritis (OA) is characterized by the destruction of the extracellular matrix and the loss of chondrocyte function [1,2]. Although OA affects a large proportion of the population there are few, if any, effective therapies available today that alter the pathobiologic course of the disease [3]. For many years, scientists have been searching for ways to inhibit the process of the disease and slow the progression of joint damage [4]. This is the driving force behind numerous ongoing efforts to develop new tissue engineering-based strategies for the treatment of OA $[5,6]$.

\footnotetext{
* Correspondence: tamonkabata@yahoo.co.jp

'Department of Orthopaedic Surgery, Graduate School of Medical Science,

Kanazawa University, 13-1, Takara-machi, Kanazawa 920-8641, Japan

Full list of author information is available at the end of the article
}

Mesenchymal stem cells (MSCs), with the capacity to differentiate into a variety of cells including osteoblast, tendon, muscle, adipose tissue, and chondrocyte [7, 8], are used in cellular therapy for a broad spectrum of diseases [9]. In a degenerative disease such as OA, the stem cells are exhausted and their capability for proliferation and differentiation decreases [10]. Systemic or local stem cell treatment can promote repair of the articular cartilage [8], but studies have increasingly demonstrated the low survival rate of the transplanted stem cells [11], so recent research has focused on treatments involving the paracrine effect of stem cells. Although stem cells are primarily thought to act through tissue differentiation, they can also act in a paracrine manner via the production of soluble anti-inflammatory factors $[8,12,13]$.

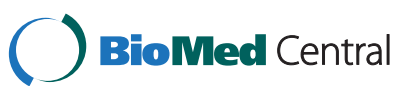

(c) 2015 Kuroda et al. Open Access This article is distributed under the terms of the Creative Commons Attribution 4.0 International License (http://creativecommons.org/licenses/by/4.0/), which permits unrestricted use, distribution, and reproduction in any medium, provided you give appropriate credit to the original author(s) and the source, provide a link to the Creative Commons license, and indicate if changes were made. The Creative Commons Public Domain Dedication waiver (http://creativecommons.org/publicdomain/zero/1.0/) applies to the data made available in this article, unless otherwise stated. 
In this study, we investigated the clinical application of one type of stem cells, adiposed-derived stem cells (ADSCs), in various fields such as bones, peripheral nerves, menisci, and ligaments [14-16]. ADSCs are safe; they can easily be isolated from subcutaneous adipose tissue and cultured in large quantities, making them a good source of tissue stem cells. Some reports have described the efficacy of an intra-articular injection of ADSCs in animal OA models. [3, 8, 12, 17, 18]. However, the role of ADSCs in the treatment of osteoarthritis is not clear $[7,9,12,19]$.

The primary purpose of this study was to determine whether intra-articularly injected ADSCs prevented or slowed articular cartilage degeneration during osteoarthritis (OA) development in a rabbit anterior cruciate ligament transection (ACLT) model; in particular we focused on the paracrine effect of ADSCs. Secondarily, the mechanism underlying the paracrine effects of ADSCs on chondrocytes was investigated in vitro.

\section{Methods}

The experimental protocol, using an animal model, was approved by the Institute for Experimental Animals, Kanazawa University Advanced Science Research Center. Surgery was performed in accordance with the Guide for the Care and Use of Laboratory Animals published by the US National Institutes of Health (NIH publication no.85-23, revised 1996), and using aseptic techniques.

\section{Animals}

Skeletally mature female Japanese white rabbits, weighing between 2.5 and $3.0 \mathrm{~kg}$, were used for this experiment.

\section{Adipose-derived stem cells}

ADSCs were isolated by modifying a previously reported method [14, 20]. Adipose tissue (1.5 g) was harvested from the posterior cervical subcutaneous adipose tissue of a rabbit and washed with phosphate-buffered saline (PBS) (Wako, Osaka, Japan). The tissue was cut into strips over a period of $5 \mathrm{~min}$. Collagenese (Wako) was dissolved in PBS so that its concentration would be $0.12 \%$ in $25 \mathrm{ml}$, and was used to digest adipose tissue at $37{ }^{\circ} \mathrm{C}$ for $45 \mathrm{~min}$ in a water bath. The mixture was shaken every 15 min during the digestion period. Immediately after the reaction was completed, $25 \mathrm{ml}$ of Dulbecco's modified Eagle's medium, DMEM (Wako), was added to neutralize collagenase activity. The resulting solution was filtered. The filtrate was centrifuged at $1300 \mathrm{rpm}$ for $6 \mathrm{~min}$ at $25^{\circ} \mathrm{C}$, and the supernatant was removed. Next, a pallet of ADSCs was seeded at $5 \times 10^{4}$ cells $/ \mathrm{cm}^{2}$ in $60.1-\mathrm{cm}^{2}$ tissue culture dishes and cultured with complete medium, DMEM containing $10 \%$ fetal bovine serum (FBS), 100 units/ $\mathrm{ml}$ penicillin, and $100 \mu \mathrm{g} / \mathrm{ml}$ streptomycin. After being cultured for 1 week, the cells were harvested with $0.25 \%$ trypsin-EDTA, centrifuged at $1300 \mathrm{rpm}$ for $6 \mathrm{~min}$, and washed twice with PBS. The obtained cells were used for intra-articular injections in vivo and coculture assays in vitro.

\section{In vivo experiments}

\section{Induction of experimental OA}

Twelve rabbits were used for the in vivo experiments. All were anesthetized by intramuscular injection of ketamine hydrochloride $(35 \mathrm{mg} / \mathrm{kg}$ body weight; Sankyo Pharmaceutical, Tokyo, Japan) and xylazine $(5 \mathrm{mg} / \mathrm{kg}$ body weight; Bayer, Tokyo, Japan), and intravenous injection of pentobarbital sodium $(40-50 \mathrm{mg} / \mathrm{kg}$ body weight; Abbott Laboratories, Chicago, IL, USA).

Traumatic degeneration was induced as previously described for the anterior cruciate ligament model [21, 22]. This model is characterized by OA-like damage. Hayashi et al. noted that rabbits show considerable individual variability in osteoarthritis progression at 4 weeks after ACLT [23]. As they suggested, we used matched-pair analysis to examine the paracrine effect of ADSCs on osteoarthritis progression in a stricter manner.

Both knees were shaved and disinfected with iodine. ACLT was performed as described by Yoshioka et al. [22]. Briefly, a medial parapatellar incision was made and an arthrotomy was performed. The patella was dislocated laterally and the knee placed in full flexion. The ACL was visualized and transected with a No.11 blade. An anterior drawing test was performed gently to confirm that the ACL was transected completely. The joint was irrigated with sterile saline and closed. A same operation was performed in the contralateral knee. The knee was opened and the patella was dislocated. After gently performing the anterior drawing test, the joint was irrigated and closed. After the operation, free activity was allowed in the cage without immobilization.

\section{Injection of ADSCs}

ADSCs were isolated from the subcutaneous adipose tissue 3 weeks after ACLT and cultured for 1 week as described above.

For matched -pair analysis of ADSCs, 12 rabbits (24 knees) were used. At 4, 5, 6 weeks after ACLT, ADSCs $\left(2.0 \times 10^{6}\right.$ cells $)$ in $100 \mu \mathrm{l} \mathrm{PBS}$ and $0.1 \mathrm{~mL}$ hyaluronic acid (Synvisc ${ }^{\circ}$; kindly provided by Teijin Limited, Japan) were intra-articularly injected into the left knee, using a 23 gauge needle. In right knees, the same volume of plain PBS and and hyaluronic acid were injected as a control. Immediately after injection, the rabbit was kept down for $5 \mathrm{~min}$ so that injected ADSCs could be attached around the synovium. 
Femoral condyles from both knees were harvested at 8 and 12 weeks after surgery following the intravenous injection of $6 \mathrm{ml}$ sodium pentobarbital.

\section{Macroscopic analysis}

The femoral condyles were dissected and stained with India ink (American MasterTech, CA, USA). Macroscopic pictures were taken using a Panasonic LUMIX digital camera (Panasonic, Tokyo, Japan). Gross findings were classified and scored as described in our previous reports $[4,23,24]$. The medial and lateral femoral condyles were individually scored from grades 0 to 5 and the two scores were summed to obtain a cumulative macroscopic osteoarthritis score. A blind assessment was then independently conducted by two individual examiners (KK, TK) and the scores from the two examiners were averaged to obtain an overall score.

\section{Histological analysis}

The dissected distal femurs were fixed in a $4 \%$ paraformaldehyde solution after gross morphological examination. The specimens were decalcified in $4 \%$ EDTA solution, dehydrated with a gradient ethanol series, and embedded in paraffin blocks.

Ten coronal sections were prepared in the coronal plane through the middle of the femoral condyles, and one section from each sample, which included the most severely degenerated area, was used for each of the histological analyses.

The specimens were stained with safranin $\mathrm{O}$ or $\mathrm{H} \& \mathrm{E}$ using standard procedures.

Histological sections were visualized using a fluorescence microscope (Keyence Japan, Osaka, Japan), assessed in a blind manner by two individual examiners (TK, KK), and quantified according to the cartilage OA histopathology grading system methodology of the Osteoarthritis Research Society International (OARSI) [25].

\section{Immunohistochemical analysis}

Immunohistochemical examinations were performed as follows. In brief, after deparaffinization, sections were incubated with $0.3 \%$ hydrogen peroxide for $30 \mathrm{~min}$. Then, sections were treated with hyaluronidase for $60 \mathrm{~min}$ after which they incubated with mouse antihuman MMP-13 monoclonal antibody (1:20; AnaSpec Inc., San Jose, Ca, USA), or mouse anti-rabbit MMP-3 monoclonal antibody (1:50; Daiichi Fine Chemical Co. Toyama, Japan) [26]. All antibody dilutions were made in PBS. After an overnight reaction with the primary antibody at $4{ }^{\circ} \mathrm{C}$, sections were incubated with labeled polymer-HRP anti-mouse IgG (Dako, Tokyo, Japan) at room temperature for $30 \mathrm{~min}$. Signals were visualized with 3, 3'-diaminobenzidine tetrahydrochloride, and nuclei were counterstained with hematoxylin. A semi-quantitative method that assigns immunohistochemistry values as a percentage of positive cells (MMP-13, MMP-13) was provided for a complete assessment of protein expression, with a maximum score of $100 \%$ [12].

Results of the histological and immunohistochemical analyses were subjected to a blind evaluation by two observers (TK, KK).

\section{Dil labeling}

On the day of intra-articular injection, ADSCs were labeled for cell tracking with a fluorescent lipophilic tracer 1,10-dioctadecyl-3,3,30,30-tetramethylindocarbocyanine perchlorate (DiI; MolecularProbesB). For labeling, the cells were re-suspended at $1 \times 10^{6}$ cells $/ \mathrm{ml}$ in aMEM, and DiI was added at $5 \mathrm{ml} / \mathrm{ml}$ in a serum-free DMEM. After incubation for $20 \mathrm{~min}$ at $37^{\circ} \mathrm{C}$ with $5 \%$ humidified $\mathrm{CO} 2$, the cells were centrifuged at $1300 \mathrm{rpm}$ for 6 min and washed twice with PBS, then re-suspended in PBS for the injection.

An examination was performed to determine where the ADSCs existed after the intra-articular injection.

A fresh frozen coronal section containing a central portion of the knee joint was prepared using Kawamoto's method [27].

\section{in vitro}

\section{Primary chondrocyte culture}

Primary culture of chondrocytes was performed using articular cartilage tissues harvested from a rabbit. Briefly, thinly sliced cartilage tissues were incubated with 0.15 trypsin with $0.1 \%$ collagenase for one hour. Subsequently, cartilage tissues were incubated in DMEM with $0.15 \%$ collagenase for $2 \mathrm{~h} 30 \mathrm{~min}$. The cells were then collected by centrifugation, seeded into collagen I coated 24-well plates (collagenI multiwell plates, BD Falcon ${ }^{\mathrm{Tm}}$ ), and cultured with DMEM containing $10 \%$ FBS supplemented with 100 units $/ \mathrm{ml}$ penicillin and $100 \mathrm{mg} / \mathrm{ml}$ streptomycin at $37{ }^{\circ} \mathrm{C}$ in a humidified atmosphere of $5 \%$ $\mathrm{CO} 2 / 95 \%$ air. Chondrocytes were grown in monolayer cultures, and were passaged when reaching confluence. Cells at the second passage were used for the assay.

\section{Co-culture assay}

To confirm the paracrine effect of ADSCs for chondrocyte, we used the co-culture system (Fig. 1).

The co-culture groups were established between ADSCs $\left(5 \times 10^{3}\right.$ cells/well) in Cell culture inserts (Cell Culture inserts, $0.4 \mu \mathrm{m}$ pores, BD Falcon $\left.{ }^{\mathrm{Tm}}\right)$ and chondrocytes $\left(5 \times 10^{3}\right.$ cells/well) in twelve-well plates (Cell Culture Insert Companion Plates, BD Falcon ${ }^{\mathrm{Tw}}$ ) in DMEM. The control group was established between no cells in Cell culture inserts and chondrocytes only in twelve-well plates $\left(5 \times 10^{3}\right.$ cells/well) in DMEM. 


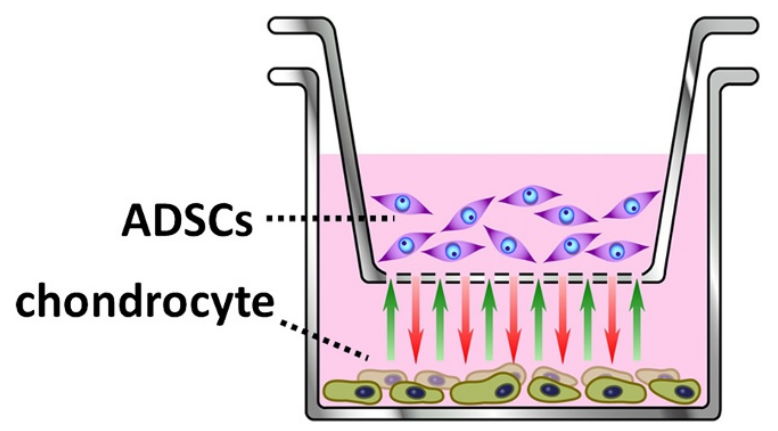

Fig. 1 The co-culture system is comprised of ADSCs in Cell culture inserts and chondrocytes in twelve-well plates. ADSCs in itself cannot pass cell culture inserts, but but secreted factors from ADSCs can pass cell inserts and affect chondrocytes

After $48 \mathrm{~h}$, cell viability of the chondrocyte group was determined using the MTT assay and compared to that of the co-culture group.

Subsequently, to confirm the paracrine effect of ADSCs for chondrocyte under TNF- $\alpha$, the culture experiments were divided into 3 groups: chondrocytes (control); chondrocytes with TNF- $\alpha$ (10 ng/mL) (TNF- $\alpha)$; and co-culture of ADSCs and chondrocytes with TNF- $\alpha$ (10 ng/mL) (ADSCs). After $48 \mathrm{~h}$, cell viability of the chondrocytes was determined using the MTT assay and compared among the three groups.

Next, $72 \mathrm{~h}$ after TNF- $\alpha$ stimulation, the concentration of MMP-13 in the three groups was measured by ELIZA. The Human Biotrak MMP-13 ELIZA kit (GE Healthcare) was used because these kits were previously shown to be suitable for assaying rabbit MMPs [28, 29].

We believe that quantifying the cellular survival rate enabled us to evaluate the chondrocyte proliferative effects of the paracrine effect of ADSCs, while the MMP-13 quantification allowed us to evaluate the chondrocyte matrix protection effects. TNF- $\alpha$ stimulation induced chondrocyte apoptosis and reproduced the clinical condition of OA.

\section{Statistical analysis}

Statistical analyses were performed using SPSS ver.19.0 (SPSS, Inc, Chicago, Ill). The results are shown as the mean \pm standard deviation (SD). The unpaired $t$-test was used. In all analyses, $P<.05$ indicates statistical significance.

\section{Results}

In vivo

\section{Macroscopic analysis}

At 8 weeks after ACLT, severe erosion in both medial and lateral femoral condyles was observed in the control group; $75 \%$ of the condyles were graded "erosion". At the same time, in the ADSC group, near normal cartilage or fibrillation was observed; only $25 \%$ of the condyles were graded "erosion". In addition, the areas of damaged cartilage appeared to be smaller than those in the control knees in each rabbit.

Figure 2a shows an example of a typical control and ADSC-treated condyle, 8 weeks after ACLT, stained with india ink. In the control knees, erosions in both the medial and lateral condyles can be seen. On the other hand, in the ADSC-treated knees, no erosion was observed; there were no macroscopically identifiable cartilage lesions in the medial condyle, and little fibrillation in the lateral condyle.

The mean macroscopic OA score (8 weeks) for the control group was $8.2 \pm 1.5$ while the ADSC group had a mean score of $4.7 \pm 2.8$ (Fig. $2 \mathrm{~b}$ ); the lower score for the ADSC group indicates less damage to the cartilage surface. This was a statistically significant difference $(P=0.019)$.

At 12 weeks after ACLT, severe erosion was observed in both groups. The mean macroscopic OA score for the control group was $7.5 \pm 2.3$ while the ADSC group had a mean score of $5.7 \pm 2.3$ (Fig. 2c). There was no statistically significant difference $(P=0.20)$.

\section{Histological analysis}

Histologically, 8 weeks after ACLT control knees showed an obvious loss of cartilage in both the medial and lateral condyles, while the cartilage matrix was predominantly retained in the ADSC-treated knees.

Figure 3a shows a typical histological section from a control group condyle and an ADST-treated condyle. The control group sections showed more cartilage defects.

At 8 weeks after ACLT, the mean OARSI score for the control group was $13.0 \pm 8.9$ while the ADSCs group had a mean score of $25.6 \pm 4.1$ (Fig. 3c). This was a statistically significant difference $(P=0.016)$.

At 12 weeks after ACLT, greater loss of cartilage was observed in both the control and ADSC groups (Fig. 3b). The mean OARSI score for the control group was $20.0 \pm 2.8$ while the ADSC group had a mean score of $19.0 \pm 7.1$ (Fig. 3d). There was no statistically significant difference between the two $(P>0.05)$.

\section{Immunohistochemical analysis}

MMP-3 and MMP-13 are major proteases degrading the extracellular matrix. The expression of these enzymes was analyzed by immunohistochemistry using samples prepared 8 weeks after ACLT.

For MMP-3, there were no significant differences between the number of positive cells in the ADSC and control groups (data are not shown).

The proportion of MMP-13-positive cells, however, was significantly lower in sections of the ADSC groups than in sections of the control group (Fig. 4b). 

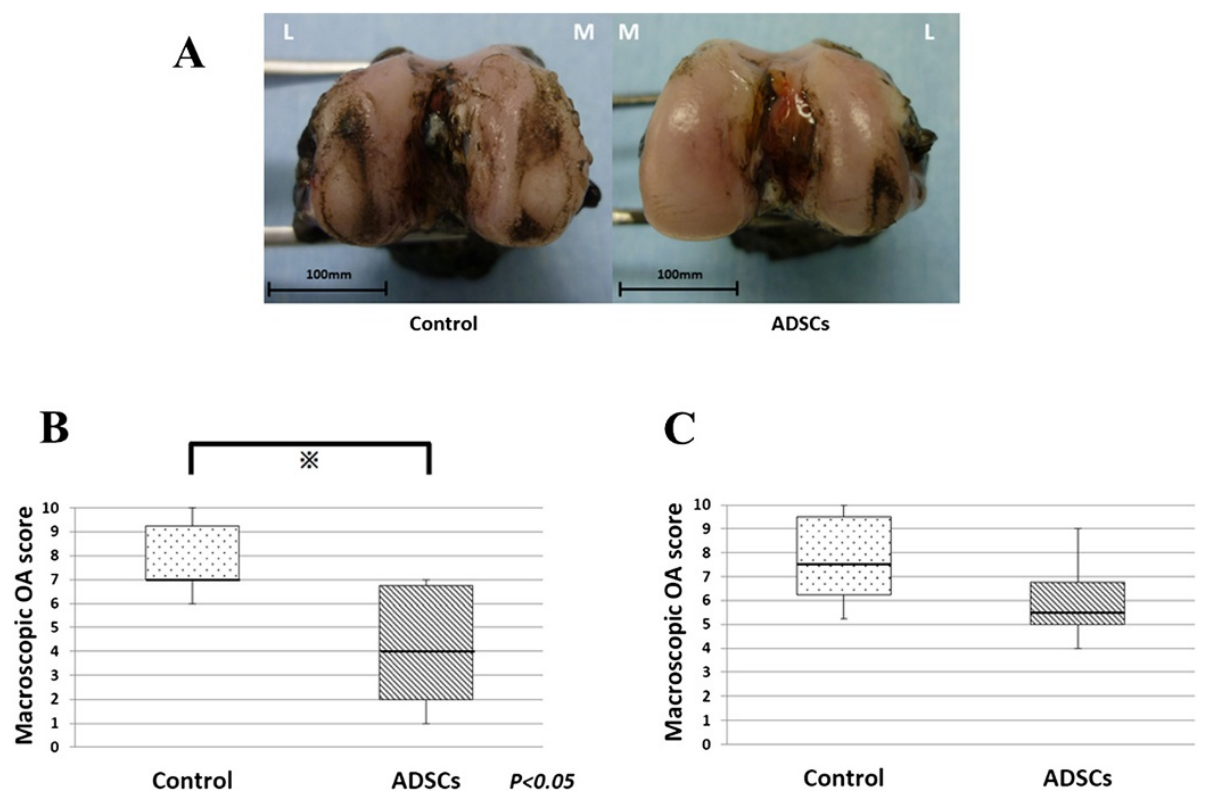

Fig. 2 Macroscopic analyses of the femoral condyles. a Representative specimen 8 weeks after ACLT. To remove individual viability, both sides of the knees of the same individuals are shown. The surface of the cartilage was stained with India ink to identify any fibrillation and erosion. Laterality is shown as medial (M) and lateral (L). b Macroscopic osteoarthritis score 8 weeks after ACLT $(n=6)$. c Macroscopic osteoarthritis score 12 weeks after $\operatorname{ACLT}(n=6)$

\section{Dil labeling}

DiI positive areas are shown in Fig. 5a and b. Figure 5a reveals that intra-articular injected cells survived and homed to the subintimal layers of the synovium and ligament, but not the cartilage, 8 weeks after ACLT. On the other hand, at 12 weeks after ACLT, no DiI positive cells were observed (Fig. 5b).

\section{in vitro}

\section{Co-culture assay}

To confirm the paracrine effect of ADSCs on chondrocytes, their cell viability was evaluated using a co-culture system (Fig. 5).

The cell viability of chondrocytes co-cultured with ADSCs was higher than that of chondrocytes cultured alone (Fig. 6a). Similar results were obtained under TNF- $\alpha$ stimulation. The cell viability of chondrocytes co-cultured with ADSCs was higher than that of those cultured alone under TNF- $\alpha$ stimulation (Fig. 6b).

To confirm the paracrine effect of ADSCs on MMP-13 expression, the concentration of MMP-13 in the coculture and control groups was evaluated by ELIZA. At $72 \mathrm{~h}$ after TNF- $\alpha$ stimulation, the concentration of MMP-13 in the medium of the co-culture group was lower than that in the medium of the chondrocyte alone group, as shown in Fig. 7. This indicates that the expression of MMP-13 was reduced by the paracrine effect of the ADSCs.

\section{Discussion}

In this study, we found that intra-articularly injected ADSCs inhibited cartilage degeneration progression in a rabbit OA model, and homed to intra-articular soft tissue (the subintimal layers of the synovium, ligament). Furthermore, we focused on the paracrine effects of ADSCs; intra-articularly injected ADSCs could secrete a liquid factor having chondro-protective effects, such as chondrocyte proliferation and cartilage matrix protection.

Adipose tissue is known to play a key role in energy balance and metabolic disorders [9]. Moreover, a recent study demonstrated that adipose tissue hosts multipotent stem cells [30]. These cells, called adipose tissuederived stromal cells or adipose stem cells (ASCs), were first reported in 2001 by Zuk et al. [20]. ADSCs have the capacity to differentiate into a variety of cells, including adipocytes, osteoblasts, chondrocytes, and myocytes under specific culture conditions in vitro [31].

On the other hand, some reports note that when the chondrogenic potential of MSCs derived from bone marrow and from adipose tissue were compared in vitro and in vivo, chondrogenesis was superior in those derived from bone marrow [32, 33].

ADSCs are used for chondro-protective therapy because autologous ADSCs can easily be isolated in large amounts from subcutaneous adipose tissue [14]. Also ADSCs can be harvested less invasively than BMSCs, and many more stem cells can be harvested at one time [34, 35]. In clinical applications, autologous ADSCs should be used from the 


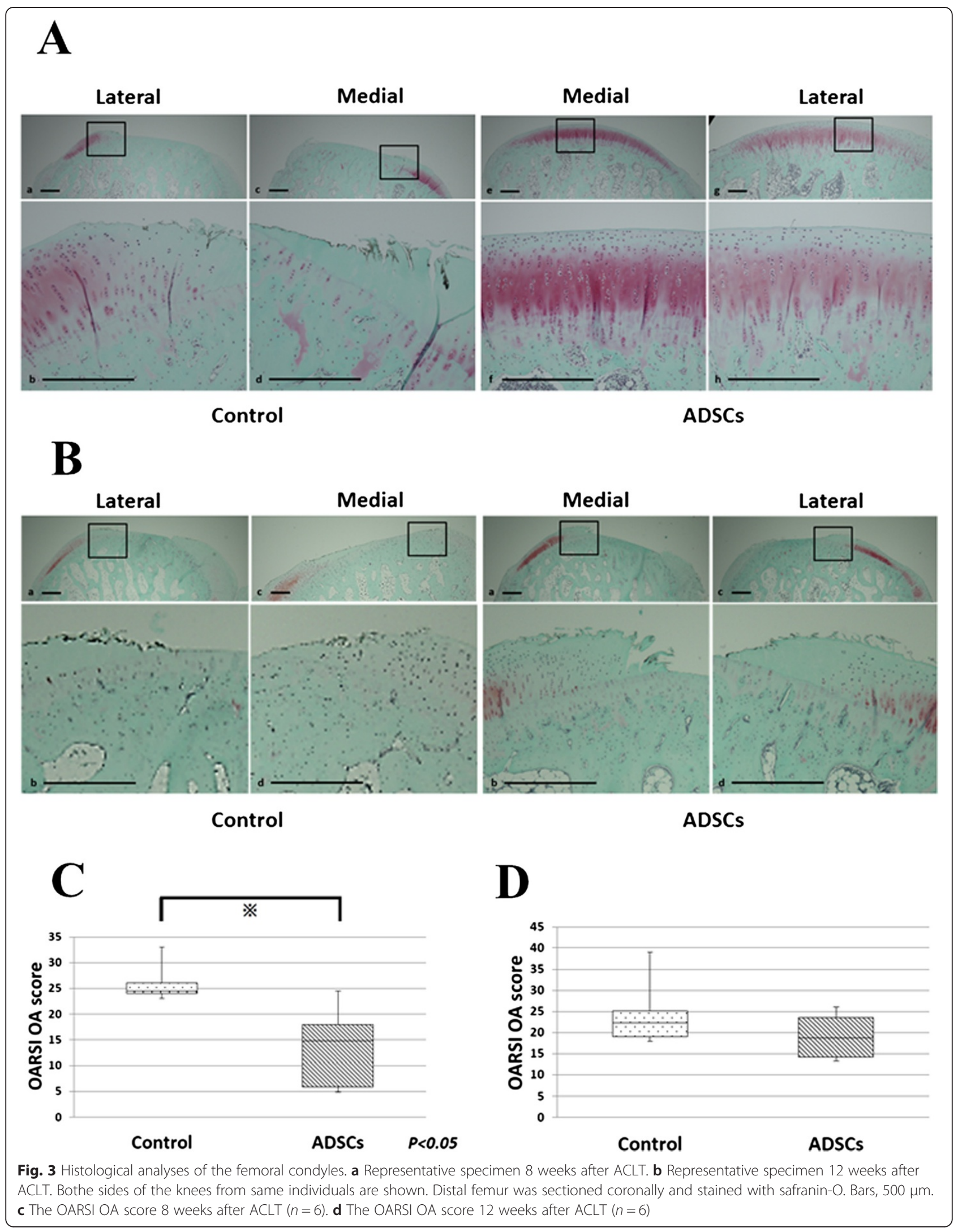




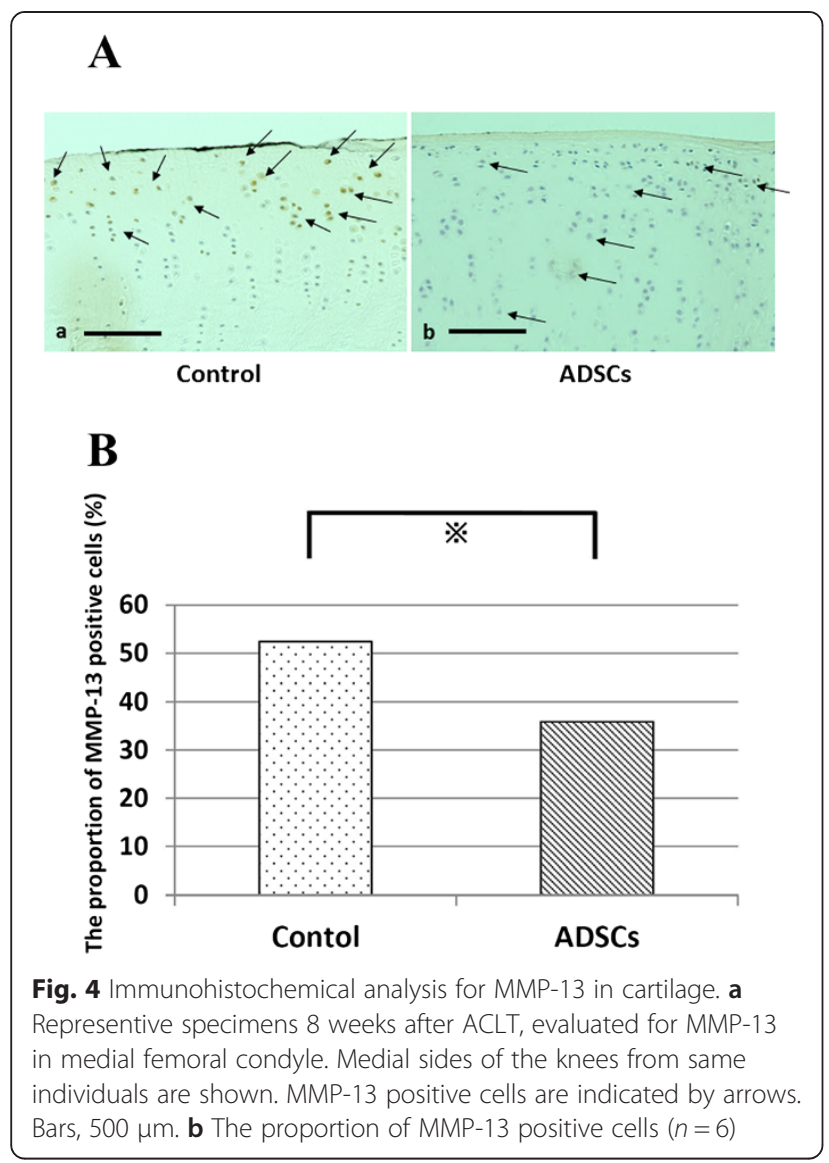

perspective of safety, and ADSCs should be minimally manipulated. This is why ADSCs are emerging as an alternative to BMSCs in the orthopaedic field [17].

We also focused on the paracrine effect of ADSCs as a new method for chondro-protective therapy.

It is generally believed that the primary therapeutic effect of stem cells occurs through tissue differentiation because stem cells can differentiate toward various types of cells [36]. Lee et al. reported that injected MSCs were present in neocartilage [37]. On the other hand, bioactive factors secreted by stem cells can influence the local tissue environment and exert a protective effect. [38, 39]. Arnold Caplan first proposed MSCs as a trophic mediator for tissue repair [38]. In addition, MSCs have a trophic, antiinflammatory and immunosuppressive action, by modulating $\mathrm{T}$ and $\mathrm{B}$ cells and inducing the expression of anti -inflammatory factors, such as interleukin 10 (IL-10), IL-1 receptor antagonist (IL-1 RA), or prostaglandin E2 (PGE2) [17].

In this study, intra-articularly injected DiI-ADSCs homed to intra-articular soft tissue (the subintimal layers of the synovium, ligament) 8 weeks after ACLT, but there were few in articular cartilage. The above results indicate that the paracrine effect of ADSCs which homed in intra-articular soft tissue contributed largely

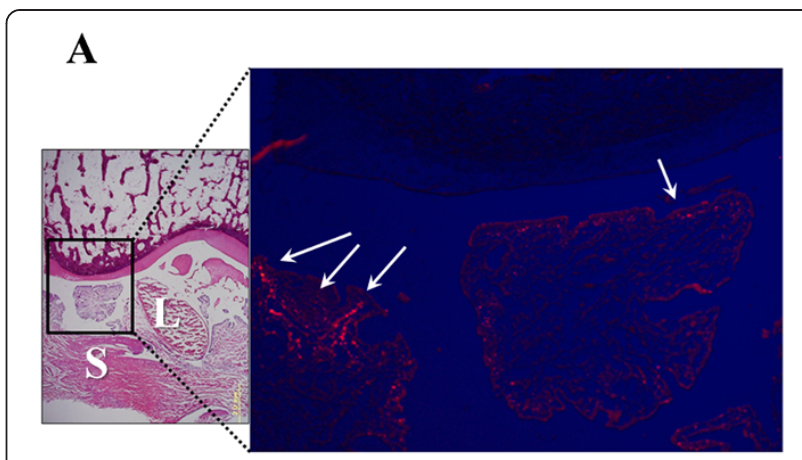

\section{B}

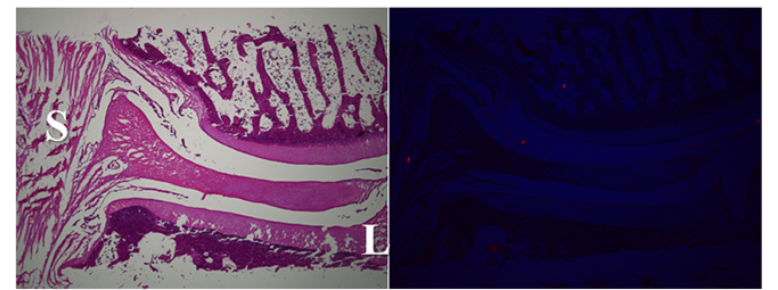

Fig. 5 Dil labeling at 8 weeks (a) and 12 weeks (b) after ACLT; After intra-articular injection of ADSCs labeled with Dil dye, frozen sections were prepared and then stained with hematoxylin and eosin. Dil positive cells survived and homed to the subintimal layers of the synovium (S) and ligament (L), not in the cartilage at 8 weeks after ACLT

to the inhibition of cartilage degeneration progression, not regeneration by ADSC differentiation.

There have been many reports concerning the therapeutic properties of ADSCs for cartilage defects $[40,41]$. In recent years, several researchers have suggested the effectiveness of ADSCs as treatment for OA [7-9, 12, 17, 19, 42].

In our study, osteoarthritis progression was obviously milder in the ADSC-treated knees than in the control knees 8 weeks after ACLT in both macroscopic and histological evaluation. This is the data supporting the efficacy of ADSCs for OA treatment that other reports also have suggested.

Despite the results showing the chondro-protective effects of ADSCs, it is important to mention that the mechanism by which ADSC therapy facilitates tissue repair is still unclear. Toghraie et al. indicated that the injected ADSCs may regenerate degenerative tissue after directly filling the lesion [7], but there is insufficient evidence for this. Other reports have suggested that that injected ADSCs indirectly stimulate the secretion of bioactive factors such as cytokines and growth factors [9, 12, 42, 43]. We also focused on the paracrine effects of ADSCs, especially the effect on chondrocytes. We investigated these paracrine effects using a co-culture system. 

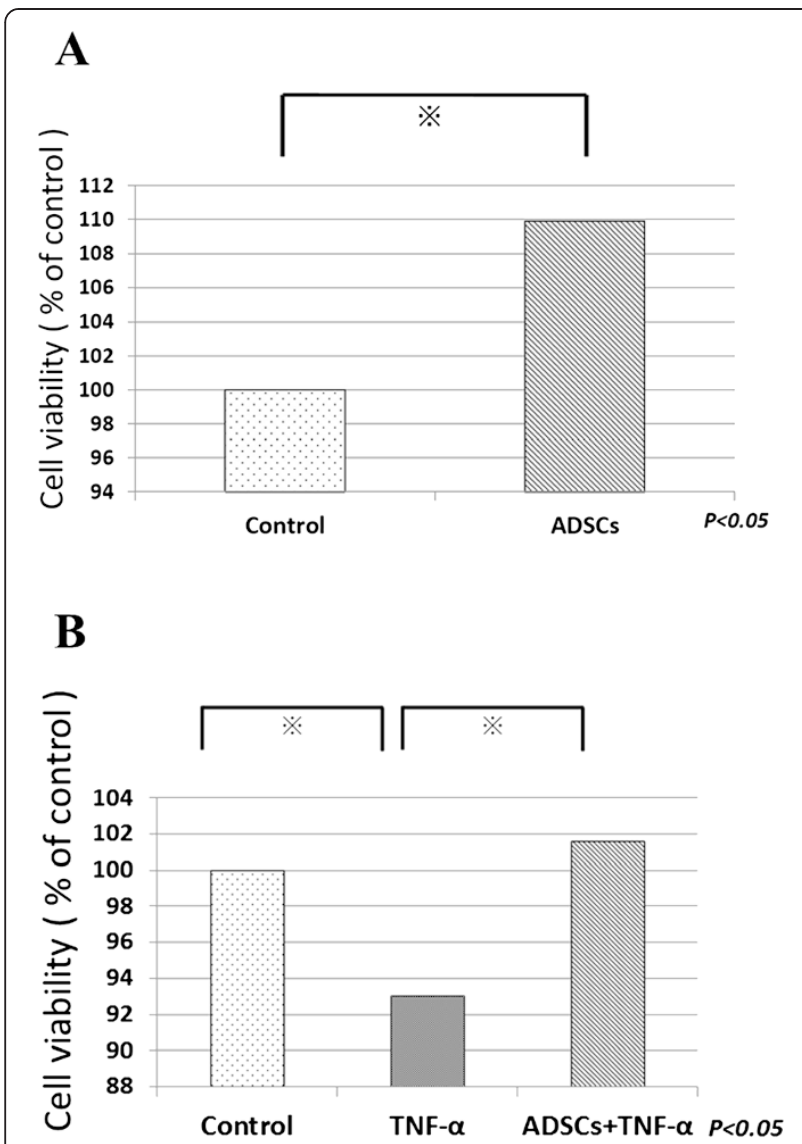

Fig. 6 Cell viability of chondrocyte was determined using the MTT assay and compared (a) between chondrocyte group and co-culture group, (b) between each groups; chondrocytes (control), chondrocytes with TNF-a (10 ng/mL) (TNF-a); and co-culture of ADSCs and chondrocytes with TNF-a (10 ng/mL) (ADSCs + TNF-a)

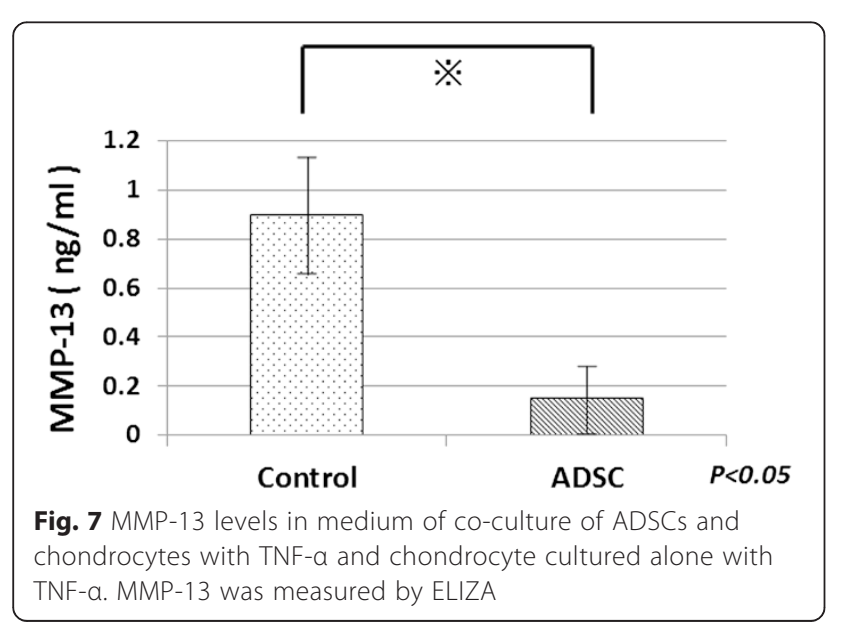

Wu et al. investigated the paracrine effect of MSCs on chondrocytes using a co-culture system [44]. Tsuchiya et al. first reported that co-culture of BMSCs and articular chondrocytes enhanced matrix production [45]. Meanwhile, Hildner et al. also reported increased cartilage formation in the co-culture of chondrocytes with ADSCs [46].

Our data showed a significant increase of chondrocytes in co-culture with ADSCs. Furthermore, although TNF- $\alpha$ led to the death of chondrocytes (Fig. 6b Control VS TNF- $\alpha$ ), the effect of TNF- $\alpha$ was suppressed when chondrocytes were co-cultured with ADSCs (Fig. 6b TNF- $\alpha$ VS ADSCs + TNF- $\alpha$ ). These results indicate that the paracrine effects of ADSCs have effects such as regulating chondrocyte viability in osteoarthritis.

It is believed that MMP13 causes damage to cartilage in $\mathrm{OA}$, and that this is mediated by chondrocytes in an autocrine or paracrine manner [47]. We showed that production of MMP-13 in articular chondrocytes was reduced when they are treated with injected ADSCs in vivo, and the MMP-13 concentration of culture fluid was also reduced when co-cultured with ADSCs in vitro. These data suggest that ADSCs protect the articular cartilage from degeneration by inhibiting MMP13 expression and secreting multiple growth factors.

In our results, intra-articularly injected ADSCs had an inhibiting effect on cartilage degeneration progression 8 weeks after ACLT, but did not show a significant effect at 12 weeks. Furthermore, no DiI positive cells were observed 12 weeks after ACLT. This is why intraarticularly injected ADSCs might not survive in a joint, so the paracrine effect lasted only weeks.

\section{Conclusions}

Intra-articularly injected ADSCs inhibited cartilage degeneration progression in a rabbit OA model by homing to the synovium and secreting a liquid factor with chondro-protective effects such as regulating chondrocyte viability and cartilage matrix protection.

\section{Abbreviations}

ACLT: Anterior cruciate ligament transection; ADSCs: Adipose-derived stem cells; DMEM: Dulbecco's modified Eagle's medium; FBS: Fetal bovine serum; H\&E: Hematoxylin \& eosin; IL: Interleukin; MMP: Matrix metalloproteinase; MSCs: Mesenchymal stem cells; OA: Osteoarthritis; PBS: Phosphate-buffered saline; PG: Prostaglandin; SD: Standard deviation; TNF-a: Tumor necrosis factor.

\section{Competing interests}

The authors declare that they have no competing interests.

\section{Authors' contributions}

KK conceived the study, conducted the experiments, analyzed the data and wrote the first draft of the manuscript. TK conceived the study, analyzed the data, and provided additional advice. KHay provided additional advice. TM, YK, SI were involved in the design of the experiments. KF, KHas and DI performed the anesthesia procedures and the administration of cells into the rabbit knee joint. NS analyzed the data, provided additional advice. HT conceived the study, provided additional advice. All authors were involved in interpretation of the results. All authors commented on and accepted the submitted manuscript. All authors read and approved the final manuscript. 


\section{Acknowledgments}

The authors thank Mr. Toshiya Nomura and Ms. Yoko Kasai for their skillful technical assistance. No funding was received for this manuscript.

\section{Author details}

'Department of Orthopaedic Surgery, Graduate School of Medical Science, Kanazawa University, 13-1, Takara-machi, Kanazawa 920-8641, Japan. ${ }^{2}$ Department of Physiology, Graduate School of Medical Science, Kanazawa University, Kanazawa, Japan.

Received: 27 April 2015 Accepted: 28 August 2015

Published online: 03 September 2015

\section{References}

1. Mankin HJ, Lippiello L. Biochemical and metabolic abnormalities in articular cartilage from osteo-arthritic human hips. J Bone Joint Surg Am. 1970;52:424-34.

2. Lee SW, Song YS, Lee SY, Yoon YG, Lee SH, Park BS, et al. Downregulation of protein kinase CK2 activity facilitates tumor necrosis factor-a-mediated chondrocyte death through apoptosis and autophagy. PLoS One. 2011;29:e19163.

3. Wakitani S, Goto T, Pineda SJ, Pineda SJ, Young RG, Mansour JM, et al. Mesenchymal cell-based repair of large, full-thickness defects of articular cartilage. J Bone Joint Surg Am. 1994;76:579-92.

4. Hayashi M, Muneta T, Ju YJ, Mochizuki T, Sekiya I. Weekly intra-articular injections of bone morphogenetic protein-7 inhibits osteoarthritis progression. Arthritis Res Ther. 2008;10:R118.

5. Koh YG, Choi YJ. Infrapatellar fat pad-derived mesenchymal stem cell therapy for knee osteoarthritis. Knee. 2012;19:902-7.

6. Hardingham T, Tew S, Murdoch A. Tissue engineering: chondrocytes and cartilage. Arthritis Res. 2002;4:S63-8.

7. Toghraie FS, Chenari N, Gholipour MA, Faghih Z, Torabinejad S, Dehghani S, et al. Treatment of osteoarthritis with infrapatellar fat pad derived mesenchymal stem cells in Rabbit. Knee. 2011;18:71-5.

8. Murphy JM, Fink DJ, Hunziker EB, Barry FP. Stem cell therapy in a caprine model of osteoarthritis. Arthritis Rheum. 2003:48:3464-74.

9. ter Huurne M, Schelbergen R, Blattes R, Blom A, de Munter W, Grevers LC, et al. Antiinflammatory and chondroprotective effects of intraarticular injection of adipose-derived stem cells in experimental osteoarthritis. Arthritis Rheum. 2012;64:3604-13.

10. Murphy JM, Dixon K, Beck S, Fabian D, Feldman A, Barry F. Reduced chondrogenic and adipogenic activity of mesenchymal stem cells from patients with advanced osteoarthritis. Arthritis Rheum. 2002:46:704-13.

11. Toma C, Wagner WR, Bowry S, Schwartz A, Villanueva F. Fate of cultureexpanded mesenchymal stem cells in the microvasculature : in vivo observations of cell kinetics. Circ Res. 2009;13:398-402.

12. Desando G, Cavallo C, Sartoni F, Martini L, Parrilli A, Veronesi F, et al. Intraarticular delivery of adipose derived stromal cells attenuates osteoarthritis progression in an experimental rabbit model. Arthritis Res Ther. 2013;29:R22.

13. Chen L, Tredget EE, Wu PY, Wu Y. Paracrine factors of mesenchymal stem cells recruit macrophages and endothelial lineage cells and enhance wound healing. PLoS One. 2008;2:e1886.

14. Suganuma S, Tada K, Hayashi K, Takeuchi A, Sugimoto N, Ikeda K, et al. Uncultured adipose-derived regenerative cells promote peripheral nerve regeneration. J Orthop Sci. 2013;18:145-51.

15. Nomura I, Watanabe K, Matsubara H, Hayashi K, Sugimoto N, Tsuchiya H. Uncultured Autogenous Adipose-derived Regenerative Cells Promote Bone Formation During Distraction Osteogenesis in Rats. Clin Orthop Relat Res. 2014;472:3798-806

16. Fang X, Murakami H, Demura S, Hayashi K, Matsubara H, Kato S, et al. A novel method to apply osteogenic potential of adipose derived stem cells in orthopaedic surgery. PLoS One. 2014;19:e88874.

17. Veronesi F, Maglio M, Tschon M, Aldini NN, Fini M. Adipose-derived mesenchymal stem cells for cartilage tissue engineering: state-of-the-art in in vivo studies. J Biomed Mater Res A. 2014;102:2448-66.

18. Wakitani S, Imoto K, Yamamoto T, Saito M, Murata N, Yoneda M. Human autologous culture expanded bone marrow mesenchymal cell transplantation for repair of cartilage defects in osteoarthritic knees. Osteoarthritis Cartilage. 2002;10:199-206.

19. Guercio A, Di Marco P, Casella S, Cannella V, Russotto L, Purpari G, et al. Production of canine mesenchymal stem cells from adipose tissue and their application in dogs with chronic osteoarthritis of the humeroradial joints. Cell Biol Int. 2012:36:189-94.

20. Zuk PA, Zhu M, Mizuno H, Huang J, Futrell JW, Katz AJ, et al. Multilineage cells from human adipose tissue: implications for cell-based therapies. Tissue Eng. 2001;7:211-28.

21. Vignon E, Bejui J, Mathieu P, Hartmann JD, Ville G, Evreux JC, et al. Histological cartilage changes in a rabbit model of osteoarthritis. J Rheumatol. 1987;14:104-6.

22. Yoshioka M, Coutts RD, Amiel D, Hacker SA. Characterization of a model of osteoarthritis in the rabbit knee. Osteoarthritis Cartilage. 1996:4:87-98.

23. Hayashi M, Muneta T, Takahashi T, Ju YJ, Tsuji K, Sekiya I. Intra-articular injections of bone morphogenetic protein-7 retard progression of existing cartilage degeneration. J Orthop Res. 2010;28:1502-6.

24. Inoue A, Takahashi KA, Arai Y, Tonomura H, Sakao K, Saito M, et al. The therapeutic effects of basic fibroblast growth factor contained in gelatin hydrogel microspheres on experimental osteoarthritis in the rabbit knee. Arthritis Rheum. 2006;54:264-70.

25. Pritzker KP, Gay S, Jimenez SA, Ostergaard K, Pelletier JP, Revell PA, et al. Osteoarthritis cartilage histopathology: grading and staging. Osteoarthritis Cartilage. 2006;14:13-29.

26. Mitsui H, Aoyama T, Furu M, Ito K, Jin Y, Maruyama T, et al. Prostaglandin E2 receptor type 2-selective agonist prevents the degeneration of articular cartilage in rabbit knees with traumatic instability. Arthritis Res Ther. 2011;13:R146.

27. Kawamoto T. Use of a new adhesive film for the preparation of multipurpose fresh-frozen sections from hard tissues, whole-animals, insects and plants. Arch Histol Cytol. 2003;66:123-43.

28. Hashizume M, Koike N, Yoshida H, Suzuki M, Mihara M. High molecular weight hyaluronic acid relieved joint pain and prevented the progression of cartilage degeneration in a rabbit osteoarthritis model after onset of arthritis. Mod Rheumatol. 2010;20:432-8.

29. François M, Richette P, Tsagris L, Fitting C, Lemay C, Benallaoua M, et al. Activation of the peroxisome proliferator-activated receptor alpha pathway potentiates interleukin-1 receptor antagonist production in cytokine-treated chondrocytes. Arthritis Rheum. 2006:54:1233-45.

30. Puissant B, Barreau C, Bourin P, Clavel C, Corre J, Bousquet C, et al. Immunomodulatory effect of human adipose tissue-derived adult stem cells: comparison with bone marrow mesenchymal stem cells. $\mathrm{Br} J$ Haematol. 2005;129:118-29.

31. Zuk PA, Zhu M, Ashjian P, De Ugarte DA, Huang Jl, Mizuno H, et al. Human adipose tissue is a source of multipotent stem cells. Mol Biol Cell. 2002:13:4279-95.

32. Hatsushika D, Muneta T, Horie M, Koga H, Tsuji K, Sekiya I. Intraarticular injection of synovial stem cells promotes meniscal regeneration in a rabbit massive meniscal defect model. J Orthop Res. 2013;31:1354-9.

33. Sakaguchi Y, Sekiya I, Yagishita K, Muneta T. Comparison of human stem cells derived from various mesenchymal tissues: superiority of synovium as a cell source. Arthritis Rheum. 2005;52:2521-9.

34. Strem BM, Hicok KC, Zhu M, Wulur I, Alfonso Z, Schreiber RE, et al. Multipotential differentiation of adipose tissue-derived stem cells. Keio J Med. 2005;54:132-41.

35. Fraser JK, Zhu M, Wulur I, Alfonso Z. Adipose-derived stem cells. Methods Mol Biol. 2008:449:59-67.

36. O'Sullivan J, D'Arcy S, Barry FP, Murphy JM, Coleman CM. Mesenchymal chondroprogenitor cell origin and therapeutic potential. Stem Cell Res Ther. 2011;18:8.

37. Lee KB, Hui JH, Song IC, Ardany L, Lee EH. Injectable mesenchymal stem cell therapy for large cartilage defects-a porcine model. Stem Cells. 2007;25:2964-71

38. Caplan Al, Dennis JE. Mesenchymal stem cells as trophic mediators. J Cell Biochem. 2006;98:1076-84.

39. Nöth U, Steinert AF, Tuan RS. Technology insight: adult mesenchymal stem cells for osteoarthritis therapy. Nat Clin Pract Rheumatol. 2008;4:371-80.

40. Schäffler A, Büchler C. Concise review: adipose tissue-derived stromal cellsbasic and clinical implications for novel cell-based therapies. Stem Cells. 2007;25:818-27.

41. Nathan S, De Das S, Thambyah A, Fen C, Goh J, Lee EH. Cell-based therapy in the repair of osteochondral defects: a novel use for adipose tissue. Tissue Eng. 2003:9:733-44.

42. Koh YG, Jo SB, Kwon OR, Suh DS, Lee SW, Park SH, et al. Mesenchymal stem cell injections improve symptoms of knee osteoarthritis. Arthroscopy. 2013;29:748-55 
43. Frisbie DD, Kisiday JD, Kawcak CE, Werpy NM, Mcllwraith CW. Evaluation of adipose-derived stromal vascular fraction or bone marrow-derived mesenchymal stem cells for treatment of osteoarthritis. J Orthop Res. 2009;27:1675-80.

44. Wu L, Cai $X$, Zhang S, Karperien M, Lin Y. Regeneration of articular cartilage by adipose tissue derived mesenchymal stem cells: perspectives from stem cell biology and molecular medicine. J Cell Physiol. 2013;228:938-44.

45. Tsuchiya K, Chen G, Ushida T, Matsuno T, Tateishi T. The effect of coculture of chondrocytes with mesenchymal stem cells on their cartilaginous phenotype in vitro. Mater Sci Eng. 2004;24:6.

46. Hildner F, Concaro S, Peterbauer A, Wolbank S, Danzer M, Lindahl A, et al. Human adipose-derived stem cells contribute to chondrogenesis in coculture with human articular chondrocytes. Tissue Eng Part A. 2009;15:3961-9.

47. Shirai T, Kobayashi M, Nishitani K, Satake T, Kuroki H, Nakagawa Y, et al. Chondroprotective effect of alendronate in a rabbit model of osteoarthritis. J Orthop Res. 2011;29:1572-7.

\section{Submit your next manuscript to BioMed Central and take full advantage of:}

- Convenient online submission

- Thorough peer review

- No space constraints or color figure charges

- Immediate publication on acceptance

- Inclusion in PubMed, CAS, Scopus and Google Scholar

- Research which is freely available for redistribution 